\title{
Tumor Suppressor Gene Inactivation Process
}

National Cancer Institute

\section{Source}

National Cancer Institute. Tumor Suppressor Gene Inactivation Process. NCI Thesaurus. Code C89809.

Any DNA sequence alteration process occurring in a tumor suppressor gene, resulting in loss of function of the gene product, and predisposing the cell to neoplastic transformation. Tumor suppressor genes are ordinarily involved in repressing cell cycle or promoting apoptosis. Inactivation of such genes permits growth inappropriately, and is an important step in the process of cellular transformation. 